\title{
Update on the Development of the Australian University Mental Health Framework
}

\author{
Penny Carlson \\ Senior Program Manager, Orygen \\ Aranya Changkaoprom \\ Project Officer, Orygen \\ Vivienne Browne \\ Associate Director \\ Strategic Relations and Policy, Orygen
}

\begin{abstract}
In 2017, Orygen published the report, Under the radar: The mental health of Australian university students. The report recommended the need for national leadership and guidance to address what appeared to be an issue of growing concern for students and the university sector. This included guidance to: a) describe reasonable expectations of universities and the mental health sector in responding to student's mental health issues; b) promote evidence-based interventions and programs for supporting student mental health within these settings; and c) highlight opportunities for partnership between universities and community mental health services.

In September 2018, the Australian Government announced funding would be provided to Orygen to develop an Australian University Mental Health Framework. As the project nears completion, this article provides an overview on the process and progress to date, including the key findings from extensive consultations across the university and mental health sectors and, importantly, with students. The article also presents the key areas of action for the university sector and the mental health sector currently articulated in a draft of the Framework, which will soon be available for wider consultation.
\end{abstract}

\section{Keywords}

mental health, university students, counselling services, framework, policy, early intervention

\section{Introduction}

In 2017, Orygen released the report Under the radar: The mental health of Australian university students (Orygen, 2017). The report aimed to:

- build an understanding on the prevalence of mental ill-health, impact and help-seeking behaviours among university students;

- identify evidence for effective interventions and good practice;

- highlight current gaps in policy, program and institution responses; and

- recommend future directions for higher education and mental health policy makers, as well as sector leaders.

The report was summarised in an article published in JANZSSA Edition 25, Volume 2 (Browne, Cass, \& Munro, 2017)

Under the radar identified that a paucity of data and research made it difficult to describe a comprehensive picture of the current prevalence and impact of mental health issues among university students. Regardless, there were some reasons for concern. These included:

- In 2016 a survey conducted by headspace and the National Union of Students found unacceptably high levels of psychological distress, self-harm and suicide-related behaviours among Australian tertiary students (Rickwood et al., 2017).

- The Australian and New Zealand Student Services Association (ANZSSA) Counselling Service Managers survey in 2013 (Andrews, 2016) which found 64\% of centre managers 
reporting that they were unable to respond to all requests within two weeks. One hundred per cent agreed that the severity and complexity of presentations had increased. ${ }^{1}$

- The annual Student Experience Survey (QILT Social Research Centre, 2017) highlighted the impact on higher education student outcomes, with students most likely to consider exiting their course due to health or stress reasons. ${ }^{2}$

The report included recommendations across a number of areas, including but not limited to:

- national leadership and coordination;

- improving data and research; and

- better coordination of services and supports with the community mental health sector.

Of particular relevance for this article was the recommendation to develop national guidance, training and monitoring mechanism of university responses to student mental health. The report noted that the higher education peak body in the United Kingdom, Universities UK, have led this approach, initially through the 'Working Group on Mental Wellbeing in Higher Education' (Universities UK \& Mental Wellbeing in Higher Education Group, 2015). Strong support from the peak body has provided clear leadership and commitment from university Vice-Chancellors. More recent iterations of this work in the UK include the Step Change Framework ${ }^{3}$ and the University Mental Health Charter $^{4}$ developed by Student Minds. Similar work to develop guidelines and/or standards in postsecondary education has commenced in Canada, through the Mental Health Commission ${ }^{5}$.

In September 2018 the Australian Government announced additional investment in research and development at Orygen, one component of which was funding to develop an Australian University Mental Health Framework (Minister for Health, 2018). The Framework aims to provide guidance to support universities and their communities to create a mentally healthy university setting which provides the best opportunities for students to thrive, educationally and personally. It is an opportunity for universities, health providers and mental health organisations to review and reflect on their current response and identify areas where policy and practice could be initiated or enhanced, and informed by good practice occurring across Australia and internationally.

It is hoped that implementation of the Framework in Australian universities and community mental health services engaged with university students will enable:

- Better identification, integration and coordination between support services for more effective, collaborative, targeted approaches to early intervention.

- Engagement with students in the creation of learning environments, organisational practices and new support models that are conducive to good mental health and wellbeing.

- Improvements in data collection, evaluation and adaptation of approaches to support continuous improvement across all stages of student mental health.

- Reduction in the number of students leaving a course early, or considering early course exit, leading to longer-term savings through increased educational attainment and improved opportunities for workforce participation (Browne \& Fava, 2019).

\footnotetext{
1 A follow up survey in 2018 found that more than $60 \%$ of institutions reported an increase in demand for counselling in 2017 compared to 2016. This increase varied from less than or equal to 5\% to greater than $2 \%$. All of the 32 responses agreed or strongly agreed that over the last decade there has been a steady increase in the complexity and severity of student mental health presentations along with an increase in the proportion of students affected (Andrews, 2019).

2 The data on this has continued to increase each year, with the 2018 Student Experience Survey finding that $45 \%$ of students considering an early course exit say it is because of health and stress (Department of Education at Training, 2019).

3 https://www.universitiesuk.ac.uk/stepchange

4 https://www.studentminds.org.uk/charter.html

5 https://www.mentalhealthcommission.ca/English/studentstandard
} 


\section{Progress to date}

Stakeholder engagement is considered critical to the eventual acceptance and uptake of the Framework. Multiple strategies and approaches have been employed to engage a large number of stakeholders for different purposes and to seek input from individuals in a variety of roles.

Key stakeholder groups have been established to inform development of the Framework, along with ongoing broader consultation including:

Advisory Group - comprising senior representatives and individual experts from the mental health sector, the university sector, young people broadly and university students. The group meets quarterly to provide guidance, advice and sector expertise related to high level Framework development.

Expert Working Groups - comprising individual experts and group representatives drawn from the mental health sector, the university sector, young people broadly and university students. Four Expert Working Groups were formed around key content areas of the Framework:

- Student mental health supports and services.

- Mentally healthy universities.

- Data to reflect, learn, adapt.

- Collaboration for continuous innovation and reform.

The groups contribute to the evidence base for interventions/actions within the Framework via surveys and structured feedback.

\section{Consultation}

Conference presentations and workshops with stakeholder groups have been undertaken to share progress, build momentum and, where appropriate, to provide opportunities for feedback. Over 400 stakeholders have been engaged via presentations and workshops between February 2019 and February 2020. In addition, a poster presentation at the International Association of Youth Mental Health conference reached an audience of over 600 individuals from more than 40 countries, including young people, researchers, mental health professionals, and policy makers.

International experts undertaking similar initiatives, in particular in Canada, the United Kingdom and New Zealand, have also been engaged to provide insights on their experiences, to share contextual perspectives and to identify opportunities for alignment. Orygen invited project leaders from Universities UK and the Mental Health Commission of Canada to share their insights on developing similar university/post-secondary guidance in their countries at a Symposium in Melbourne on 13 February 2020. The symposium brought together many of the key stakeholders engaged in the advisory and working groups.

\section{Consultation with students}

Students are at the centre of the framework, and students' needs, perspectives, and the reality of their experiences have informed the development of the project. Focus groups with university students were facilitated by an external contractor, batyr, to provide insight into student needs and preferences in relation to mental health and wellbeing. A total of 93 participants attended eight focus groups across five states. Participants reflected the diversity of the university student population, incorporating a broad range of ages, stages and areas of study; students from metropolitan and regional areas; and groups identified in the literature as being of high risk/high need in relation to mental health.

Themes emerging across the focus groups indicated that students would like to see:

- $\quad$ an increased interpersonal approach to student support and care; 
- consistent promotional and preventative activities spread throughout the year, augmenting current activities which peak around exam and assessment periods;

- increased availability of mental health services, and increased accessibility of services;

- an integrated triage system for mental health services within a 'Service Hub';

- the continuation and expansion of initiatives targeting holistic development outside of traditionally clinical mental health services;

- the creation and maintenance of safe spaces, both physically and within learning environments;

- increased mental health literacy among both students and staff; and

- mentoring opportunities, including academic and non-academic supports.

\section{Draft Framework - overview}

At the time of writing, a draft of the Framework is being prepared for broader public consultation and feedback. The draft Framework has been oriented around student wellbeing, mental health promotion and the spectrum of mental health interventions, including prevention, early intervention, treatment and recovery.

The draft Framework takes a university and mental health sector dual responsibility approach. Guidance is provided for:

- universities to create learning environments conducive to good mental health and wellbeing. Included across all areas of the university, reflecting the opportunity for a range of factors within the university setting to contribute to the mental health and wellbeing of students and the university community; and

- health providers and mental health organisations to support increased engagement with the university community and to deliver services that meet the needs of the student population.

The draft Framework is adaptable to individual contexts, enabling institutions to meet the unique needs of their student population while supporting ongoing cross-sector collaboration, improvement and innovation through a coordinated national approach.

It identifies seven key areas where universities can contribute to a whole of university response to improve students' mental health and wellbeing.

1. Leadership: University leaders at all levels share responsibility for influencing the climate and relationships within the learning community by leading organisational planning, evaluating strategies and activities focussed on mental health, as well as supporting ongoing learning and reform.

2. Governance: An evolving, institution-wide mental health and wellbeing strategy, aligned with the broader university strategic plan, will help to embed mental health as a key priority in institutional decision making. Response to student mental health requires a coordinated, integrated approach that addresses organisational, physical and cultural environments, considers organisational risks and connects to broader initiatives.

3. University community and environment: An inclusive community supports all members of the university community, including those with mental ill-health, to participate meaningfully in university life without discrimination, stigma or exclusion. Healthy connections through relationships, places, and social activities are known protective factors for mental health.

4. Teaching and learning: Incorporating mental health and wellbeing within teaching and learning programs acknowledges the importance of meeting students at their point of need and the role of universities in equipping students with lifelong, transferable skills. 
5. Workforce: Aligning student and staff mental health and wellbeing initiatives recognises the role of the whole university community in contributing to student mental health and wellbeing. Evidence suggests that creating a mentally healthy workplace and building and maintaining a mentally healthy workforce maximises wellbeing and can increase productivity.

6. University student services: Aligning and integrating the range of services and other activities that address the full spectrum of mental health as well as student wellbeing will support a coordinated, whole of university approach. The knowledge and expertise of those working in student services will help inform broader needs and opportunities to facilitate informed and aligned actions across the university to support student mental health and wellbeing.

7. Research and translation: Improving the evidence base may contribute multiple benefits for universities potentially impacting both teaching and learning and research outputs. There is an opportunity for Australian universities to pave the way for developing, testing and scaling evidencebased, innovative treatments and responses.

The draft Framework identifies a further five key areas for the mental health sector to support a response to improving students' mental health and wellbeing.

1. Partnerships: Opportunities for mental health services (including those focused on awareness raising, self-help information and supports, and the provision of stepped care through primary and tertiary services) that partner with universities exist across the continuum of interventions from supporting mental health promotion and prevention approaches to ensuring students can access essential services and supports to facilitate recovery and engagement with their education.

2. Planning: As a shared responsibility, it is important for health providers and mental health organisations to work together with universities to understand and incorporate the needs of students into their service planning arrangements.

3. Co-design services and supports: Engage with university students and existing on-campus service providers within the appropriate catchment areas to understand the university specific and unique factors that impact on students' mental health and to co-design approaches that meet students' needs.

4. Partner with universities in a stepped care approach to provide timely, accessible, affordable services and supports: Health providers and mental health organisations partnering with universities to facilitate a continuum of supports and services within a stepped care model, enabling students to access the right care at the right time, according to their needs.

5. Support educational pathways as part of a recovery focused service approach: Work with students to develop service responses that are appropriate for the breadth of the student population and provide dedicated and individualised support for their engagement or reengagement with education.

\section{Next steps}

After broader consultation, the draft Framework will be finalised in partnership with the Advisory Group. The final Framework, along with associated documents including a comprehensive evidence review, will be delivered to the Australian Government with public release shortly after.

Orygen would like to thank the members of the Australian and New Zealand Student Services Association (ANZSSA) who have contributed to the development of this work. In particular, we would like to acknowledge the valuable contribution of Dr Christie White, President ANZSSA who has participated on the project Advisory Group. 


\section{References}

Andrews, A. (2016). ANZSSA Heads of counselling services benchmarking survey 2013 summary report. Journal of the Australian and New Zealand Student Services Association, 47, 96-105.

Andrews, A. (2019). ANZSSA Heads of counselling services HOCS benchmarking survey: 2018 Summary report. Journal of the Australian and New Zealand Student Services Association, 27(1), 67-171.

Browne, V., Cass, J., \& Munro, J. (2017). Under the radar: The mental health of Australian university students. Journal of the Australian and New Zealand Student Services Association, 25(2), 2017.

Browne, V., \& Fava, N. (2019). Safeguarding the 'Mental Wealth' of Australian University Students. In J. Marychurch \& A. Sifris (Eds.), Wellness in Law: Making wellness core business. Sydney, Australia: LexisNexis Butterworths.

Department of Education at Training. (2019). Quality indicators for learning and teaching, 2018 student experience survey: National report. Canberra, Australia: Australian Government.

headspace, \& National Union of Students. (2017). National tertiary student wellbeing survey 2016.

Minister for Health. (2018). \$9 million boost for youth mental health [Press release]. Retrieved from https://www.health.gov.au/ministers/the-hon-greg-hunt-mp/media/9-million-boost-for-youth-mental-health

Orygen. (2017). Under the radar: The mental health of Australian university students. Parkville, Victoria: Orygen.

QILT Social Research Centre. (2017). 2016 Student Experience Survey National Report. Australian Government.

Rickwood, D., Telford, N., O’Sullivan, S., CRISP, D., \& Magyar, R. (2017). National Union of Students National Tertiary Student Wellbeing Survey 2016. Australia: Headspace.

Universities UK, \& Mental Wellbeing in Higher Education Group. (2015). Student mental wellbeing in higher education. Good Practice Guide. London: Universities UK.

\section{The authors may be contacted via}

penny.carlson@orygen.org.au

\section{Please cite this paper as:}

Carlson, P, Browne, V.\& Changkaoprom, A. (2020). Update on the development of the Australian University mental health framework. Journal of the Australian and New Zealand Student Services Association, 28(1), 40-45.

https://doi.org.10.30688/janzssa.2020.02 